\title{
James Haig Ferguson, LL.D., M.D., F.R.C.P.E., F.R.C.S.E., F.C.O.G.
}

DR Haig Ferguson, who died on May 2, 1934, in his seventy-second year, had for some years been the accepted doyen of the obstetrical and gynæcological section of the medical profession in Edinburgh. The son of the Rev. Wm. Ferguson, minister of Fossoway, he was distantly connected on his mother's side with Field-Marshal Earl Haig. He received his early education at the Collegiate School in Edinburgh, and graduated M.B., C.M., in the University in 1884 . After two years in resident hospital posts he became private assistant to Dr (later Sir) Halliday Croom in 1886 , and the association and friendship thus started determined Haig Ferguson's future line of work. For twenty years he carried on a large family practice, which he had inherited from Croom when the latter restricted himself to consulting work. But his reputation as an obstetrician and gynæcologist grew rapidly during these years, and in 1906, when he was appointed Assistant Gynæcologist to the Royal Infirmary, he gave up his general practice. Seven years previously he had been appointed to the staff of the Royal Maternity Hospital. Early in his career Haig Ferguson had become a Fellow of the Royal College of Physicians, which was the customary procedure for the obstetrical specialist of those days, but as the practice of gynæcology became increasingly surgical he recognised the need of obtaining a higher surgical qualification, and in 1902 he became a Fellow of the Royal College of Surgeons of Edinburgh. Of this College he ultimately became President in 1929 and held office for two years. Dr Haig Ferguson was also actively interested in the foundation, some five years ago, of the British College of Obstetricians and Gynæcologists, of which he became a Foundation Fellow.

Brought up in the tradition that teaching was an essential part of the specialist's work in a medical school such as Edinburgh, he lectured for some years in the Extra-mural School; but it is as a clinical teacher rather than a systematic lecturer that he will be remembered by his former pupils. His wide knowledge of his subject, his practical experience, and his sympathetic consideration for the personal aspect of every patient's case all combined to make him a clinical teacher who could not fail to have lasting influence over his pupils. 
For nearly fifty years Haig Ferguson was a Fellow, and on two occasions he was elected President of the Edinburgh Obstetrical Society, to which he contributed many papers, mostly records of cases of unusual interest. Probably his most valuable contribution was on a modification of the axis-traction forceps. The instrument which he devised is perhaps not so scientifically correct as Milne Murray's forceps, but in modern obstetrics the need for accurate axis-traction has largely diminished, and Haig Ferguson's forceps is a very useful and practical instrument with several real advantages over most other patterns. He took an active part in promoting the legislation embodied in the Midwives Act for Scotland, and was a member of the Central Midwives Board from its inception, and Chairman for some ten years up to the time of his death. He gave much time and thought to the important work of this Board, and was scrupulously conscientious also in his service on numerous other public bodies of which he was a member-the Council of the Queen's Institute of District Nursing, the Board of the Royal Hospital for Sick Children, and Donaldson's Hospital, amongst others.

Dr Haig Ferguson was joint author of two books on professional subjects-A Handbook of Obstetric Nursing, published in his early years in collaboration with the late $\mathrm{Dr}$ W. F. N. Haultain, and $A$ Combined Textbook of Obstetrics and Gynacology, published recently, with colleagues in Edinburgh and Glasgow.

No obituary notice of Dr Haig Ferguson would be adequate without special reference to the unusual attractiveness and nobility of his personal character. His humanity was such as to keep the personal aspect of his patients' troubles ever in the forefront of his mind, and his sympathy was so quick and understanding that all his patients found in him a tower of strength and refuge, a friend as well as a doctor.

He leaves the memory of a man of noble character, of an exemplary devotion to duty and of a personality of quite unusual charm.

He was elected a Fellow of the Society in 1904 .

R. W. J. 